\title{
Conversation, speech acts, and memory
}

\author{
ThOMas HoltgraVes \\ Ball State University, Muncie, Indiana
}

\begin{abstract}
Speakers frequently have specific intentions that they want others to recognize (Grice, 1957). These specific intentions can be viewed as speech acts (Searle, 1969), and I argue that they play a role in long-term memory for conversation utterances. Five experiments were conducted to examine this idea. Participants in all experiments read scenarios ending with either a target utterance that performed a specific speech act (brag, beg, etc.) or a carefully matched control. Participants were more likely to falsely recall and recognize speech act verbs after having read the speech act version than after having read the control version, and the speech act verbs served as better recall cues for the speech act utterances than for the controls. Experiment 5 documented individual differences in the encoding of speech act verbs. The results suggest that people recognize and retain the actions that people perform with their utterances and that this is one of the organizing principles of conversation memory.
\end{abstract}

Conversations are ubiquitous, and what people remember from them can play a role in a variety of psychological processes. Conversation memory, for example, can contribute to the perceived continuity of one's social relationships (see, e.g., Miller, deWinstanley, \& Carey, 1996), feed into and solidify impressions of others (Holtgraves, Srull, \& Socall, 1989), serve as evidence in legal proceedings (Davis \& Friedman, 2005), reflect social categorization processes (Klauer \& Wegener, 1998; Taylor, Fiske, Etcoff, \& Ruderman, 1978), contribute to the development and maintenance of the narrative self (Hermans, 1996), and so on. Yet, conversation memory has not been studied extensively by psychologists, partly due to the fact that conversations are messy; it is difficult to specify in advance what features of conversations will be attended to and remembered. In this study, I develop and test the idea that one of the organizing features of conversation memory is the speaker's intention in producing a particular remark.

Research on memory for verbal materials has demonstrated that sentences are quickly transformed into an underlying abstract meaning and that the original surface structure is lost (Ackerman, 1982; Bransford \& Franks, 1971; Brewer, 1977; Jarvella \& Collas, 1974; Kemper, 1980; Sachs, 1967, 1974; Wanner, 1974). In other words, people tend to remember what was said (the meaning), but not how it was said (the wording). There are important exceptions, of course. When wording is interpersonally important in some way, it does tend to be remembered (Holtgraves, 1997a; Keenan, MacWhinney, \& Mayhew, 1977; Kintsch \& Bates, 1977; MacWhinney, Keenan, \& Reinke, 1982; Murphy \& Shapiro, 1994; Wyer, Budesheim, Lambert, \& Swan, 1994). But in general, research on memory suggests that - with some important exceptions - people tend to remember the gist of conversation remarks rather than retain an exact representation of those remarks.
What exactly is the nature of the gist that people remember from conversations? Many models of sentence and text processing suggest that sentences are first fully analyzed and that interpretations are compositionally built up from the words clustered into constituents (Ferreira \& Clifton, 1986). For texts, these propositional representations are then integrated in order to construct a situational model (see, e.g., van Dijk \& Kintsch, 1983; see Zwaan \& Radvansky, 1998, for a review).

However, it is doubtful that conversation processing works this way. First, engaging in a conversation is cognitively demanding because interlocutors are both producing and comprehending utterances very quickly. In contrast, readers of a text can pause, backtrack, take a break, and so on. Because of the real-time demands on conversationalists, it seems likely that conversationalists will not engage in a full-blown syntactic/semantic analysis of each remark. Instead, processing may reflect a more heuristic, on-the-fly approach, or what has been called good-enough processing (Ferreira, Bailey, \& Ferraro, 2002; Sanford \& Graesser, 2006), a term that refers to instances in which comprehension involves an interpretation of language that is neither complete nor precise, but is good enough for immediate purposes.

Second, conversationalists have overarching goals they hope to achieve as they talk: to make a good impression, to be polite, to persuade someone, and so forth. But conversationalists also have much more specific intentions-intentions that are associated with a specific conversational turn or set of turns (e.g., to request, thank, apologize, etc.). People's orientation toward intention recognition is fundamental to most theories of conversation (Austin, 1962; Cohen \& Perrault, 1979; Gibbs, 1999, 2003; Grice, 1957; Searle, 1969, 1979; Sperber \& Wilson, 1986, 1995, 2002; Stone, 2005). In contrast to texts, conversations are interactive and cannot, therefore, proceed successfully unless 
there is some understanding of what each speaker is attempting to accomplish with each utterance (Clark, 1996; Clark \& Wilkes-Gibbs, 1986). This understanding of a speaker's intention should be critical to the comprehension and memory of conversation remarks.

These two features of conversation-good-enough processing and turn-by-turn intention recognition-may indicate that conversationalists try to quickly perceive a speaker's intention in producing a particular utterance. There is disagreement, however, about the exact nature of intention recognition.

\section{The Nature of Intention Recognition}

According to speech act theorists (Austin, 1962; Searle, 1969, 1979), conversational utterances involve the simultaneous performance of multiple acts: a locutionary act (i.e., propositional meaning), an illocutionary act (i.e., the force associated with the use of the utterance in a specific context), and a perlocutionary act (i.e., the effects of the performed speech act on the recipient). It is the illocutionary act that most closely captures the nature of the speaker's intention in producing a particular conversation turn. For example, when Bob says to Andy, "I definitely will do it tomorrow," his utterance will, in many contexts, have the illocutionary force of a promise. And Andy's comprehension of Bob's remark will entail his recognition that Bob is performing a promise. Illocutionary act, illocutionary force, and speech act are typically used interchangeably and generally refer to the primary act the speaker intends to perform with an utterance. ${ }^{1}$

Intention recognition is a critical component of both speech act theory and relevance theory (Sperber \& Wilson, 1986, 1995). However, speech act theory and relevance theory differ in terms of the nature of intention recognition. Following Grice (1975), Sperber and Wilson assume that each conversational utterance carries with it a presumption of relevance. In general, the presumption of relevance suggests that comprehenders will search for the first interpretation of an utterance (least effort) that yields maximum relevance. In this theory, illocutionary force recognition is not required for utterance comprehension. Hence, I will definitely do it tomorrow does not need to be categorized as a promise in order to be understood. The only exceptions to this are institutional acts, such as bidding at bridge or declaring a base-runner out; successful performance of these acts always requires illocutionary force recognition. These are exceptions, however, and the majority of conversation utterances do not require the assignment of an utterance to a particular type of speech act. In addition to relevance theory, many computational approaches to conversations also explicitly deny that speech act recognition is required for conversation understanding (Allen, 1983; Cohen \& Levesque, 1990). Rather, individuals are viewed as rational agents with specific goals and plans designed to achieve those goals. In this view, language understanding involves recognition of a speaker's goal and the role one might play in the accomplishment of that goal. It is not necessary to recognize illocutionary force to understand a speaker's utterance, although such categorizations may take place after the fact (Cohen \& Levesque, 1990).
In sum, the nature of the representation of conversation remarks is unclear. On the one hand, speech act theory suggests that illocutionary force recognition plays a critical role in the comprehension of conversation remarks. Although speech act theorists are not precise with regard to the exact nature of this process, speech act recognition represents a quick and easy summary of a speaker's intention and is hence consistent with a good-enough processing approach. On the other hand, relevance theory and certain computational models suggest that specific speech act recognition is not required for conversation comprehension.

This issue is complicated by the fact that there are many ways in which the same speech act can be performed. In this regard, a distinction can be made between speech acts that are explicit and those that are implicit. ${ }^{2}$ Explicit speech acts are relatively clear and direct and include the relevant performative verb-the verb that names (in the appropriate contexts) the speech act that it performs. I can promise to shut the door, for example, simply by saying, "I promise to shut the door." However, the use of performative verbs may be relatively rare. Instead, people will frequently perform implicit speech acts-speech acts that do not contain the performative verb naming the illocutionary force of the utterance. For example, explicit speech acts, such as I promise to do it and I forbid you to do it, can also be performed implicitly with I guarantee that I'll have it finished tomorrow and You are not allowed to do that again, neither of which contains the performative verb promise or forbid, respectively. Rather than being unusual, implicit speech acts such as these may be far more common than utterances that contain performative verbs, although this probably varies over speech acts, with some performative verbs (e.g., promise) being frequently used and others (e.g., request) being rarely used.

There are two related issues here. The first concerns whether a speaker's intention is recognized when an implicit speech act is comprehended. For example, when Bob says to Andy, "I definitely will do it tomorrow," does Andy's comprehension of Bob's utterance include activation of the concept promise, even though the utterance does not contain the verb promise?

There is now evidence demonstrating that comprehension does entail automatic speech act recognition (Holtgraves, 2007, in press; Holtgraves \& Ashley, 2001). In these experiments, participants read or heard utterances that did or did not perform specific speech acts (e.g., warn, beg, etc.). Subsequent performance on various online tasks was affected by the activation of specific speech acts. For example, with a recognition probe task, participants were slower at verifying that remind had not literally been present in the remark Don't forget to go to your dentist appointment today than in the control remark I'll bet you forgot to go to your dentist appointment today.

What is not clear, however, is whether illocutionary force also forms part of the long-term representation of an utterance. Does Andy's representation of Bob's utterance I'll definitely do it tomorrow include the illocutionary force of the utterance - that it's a promise? It is possible that illocutionary force activation will play a role during 
comprehension, but is then quickly forgotten, similar to the manner in which people quickly forget the exact wording of an utterance. Alternatively, it is possible that illocutionary force activation will play a role in comprehension and subsequently form part of the long-term representation of that utterance. In speech act theory, most illocutionary points have the logical form $\mathrm{F}(\mathrm{p})$, where $\mathrm{F}$ represents the illocutionary force and $\mathrm{p}$ represents the propositional content (Searle \& Vanderveken, 1985; Vanderveken, 1990). In this view, the long-term representation of the utterance I'll definitely do it tomorrow would be something like promise (will perform the act tomorrow). If this is the case, then several things should follow.

First, there should be a tendency for people to falsely remember conversation utterances as containing speech act verbs characterizing those utterances. A finding similar to this was reported by Schweller, Brewer, and Dahl (1976), who examined memory for a small set of utterance descriptions (rather than actual utterances). This hypothesis was tested in the present Experiments 1 through 3. Second, if illocutionary force forms part of the long-term representation of an utterance, then speech act verbs should serve as relatively good recall cues for utterances performing those speech acts. This hypothesis was tested in Experiments 4 and 5. In addition, I examined the possibility of individual differences in memory for speech acts in Experiment 5.

\section{EXPERIMENTS 1 THROUGH 5 Stimulus Development and Pretest}

The stimulus materials for these experiments consisted of a set of scenarios (adapted from Holtgraves, in press). Each scenario (two to six sentences) described a situation between two people and was followed by a remark or remarks that were said by these people. The last remark was always the target utterance (see Table 1). An attempt was made to include a large and varied set of speech acts and to use utterances that were generated by participants, not by researchers. To do this, the scenarios and remarks were selected from those in earlier research (Holtgraves, 2005a), in which participants had read brief scenarios and then generated utterances that they believed would perform a particular speech act (e.g., request, promise, thank, etc.). In order to generate implicit speech acts, participants were told that their utterance could not contain the words describing the speech acts that they were to perform. The resulting utterances were then examined for their linguistic features, and one prototypical utterance was chosen for each scenario. A separate group of participants then read the scenarios and corresponding prototypical utterances and provided a single word that they believed represented the speech act that was performed with the critical utterance. Scenarios/utterances for which a minimum of $38 \%$ of the participants provided the intended speech act were selected for use in the present research. ${ }^{3}$ This resulted in the 24 speech act scenarios ( 8 assertives, 6 directives, 6 expressives, and 4 commissives) used here and in Holtgraves (in press).

Control versions were then created for each of the 24 scenarios. The goal was to create versions of the scenarios that would share as many words as possible with the speech act scenarios, but for which the final utterance did not perform the relevant speech act. This was done in order to keep the semantic associates roughly equal for the speech act and control versions. In this way, any memory differences between the speech act and control scenarios would be due not to the semantic associates of the individual words but to the action performed with the speech act utterance (and not performed with the control utterance). In order to control for semantic associates, it was not possible to construct control versions based on a single manipulation. This limitation was due to the variety of speech act types examined in this research. Instead, several different mechanisms were used to create the controls. Specifically, control versions were constructed by (1) switching the tense of the utterance (e.g., promise: I swear I will be neater after the weekend vs. I swear I was neater after the weekend); (2) switching the sentence subject (e.g., apologize: I'm so sorry that Iruined your shirt vs. Ed is so sorry that he ruined your shirt); (3) negating the speech act (e.g., offer: If you need some help, just give me a call vs. If you

Table 1

Sample Stimulus Materials Used in

Experiments 1 Through 5 for Speech Act Compliment

Experiment 1: Utterance Descriptions

Gloria showed up at the office wearing a new coat.

Her coworker Heather (coworkers Heather and Stacy) soon saw it.

Heather told Gloria (Stacy) she liked her (Gloria's) new coat.

Experiments 2 Through 5: Conversation Utterances

Gloria showed up at the office wearing a new coat.

When her coworker Heather saw it she said to her (her friend Stacy),

Heather: "I like your (her) new coat."

\section{Recognition Test Items (Experiment 2)}

"I like your new coat." correct for speech act version, incorrect for control

"I like her new coat." correct for control, incorrect for speech act version

"I'd like to compliment you on your new coat." speech act lure for speech act version

"I'd like to compliment her on her new coat." speech act lure for control version

Note-The control versions were created by substituting the words in parentheses for the italicized words. 
need some help, don't give me a call); and (4) performing a different speech act (e.g., agree: You're right. It's wrong to experiment on animals vs. That's right. It's wrong to experiment on animals). An example of a control version based on a tense switch is presented in Table 1; all materials are presented in the Appendix.

Note that for some control versions-especially those based on switching the sentence subject-there is likely to be some activation of the relevant speech act verb (as in the apologize example above). Hence, a pretest was conducted in order to ensure that, overall, the speech act utterances were more likely to be perceived as performing the intended speech act than their matched controls (Holtgraves, in press). Participants endorsed the speech act interpretation of the speech act versions at a very high rate $(M=96.3 \%)$ and did so at a rate significantly greater than that for the matched controls $(M=63.1 \%)$. Moreover, the differences between the speech acts and control versions were significant $(p<.05)$ for each of the four manipulation types. Overall, these results provided justification for the use of these materials for studying speech act memory. At the same time, the relatively high endorsement rate of the speech act interpretation for the control versions $(M=$ $63.1 \%$ ) indicated that for many scenarios the control version did result in weak activation of illocutionary force (which works against the present hypotheses).

\section{EXPERIMENTS 1 AND 2 Recognition Memory for Conversational Utterances}

The purpose of these experiments was to examine incidental recognition memory for conversational utterances that performed specific speech acts. The two experiments were identical, except that conversational utterances were used in Experiment 2 and descriptions of conversational utterances were used in Experiment 1 (similar to Schweller et al., 1976). If illocutionary force is retained in long-term memory, participants should be more likely to falsely recognize a lure containing a relevant speech act verb after reading an utterance that performs that speech act than after reading an utterance that does not perform that speech act. For example, participants should be more likely to falsely recognize I apologize for ruining your shirt after reading I'm so sorry that I ruined your shirt than they are to falsely recognize Ed apologizes for ruining your shirt after reading $E d$ is so sorry that he ruined your shirt.

\section{Method}

Participants. Participants were Ball State University undergraduate students (Experiment 1: $N=54$; Experiment 2: $N=55$ ) enrolled in introductory psychology courses who participated for partial course credit. All participants spoke English as their first language.

Materials. There were 24 speech act scenarios, all of which were identical to the ones used in the pretest. However, in Experiment 1, the target was always a description of a conversational utterance (e.g., Bob said that he was right, that it's wrong to experiment on animals); in Experiment 2, the target was always the conversation utterance (Bob: "That's right; it's wrong to experiment on animals").

As in the pretest, there were two sets of materials, each containing the 24 target scenarios and utterances: 12 presented in the speech act version and 12 in the control version. The booklets were mirror images of each other, so that the speech act scenarios in one booklet appeared as the control scenarios in the other booklet, and vice versa. Scenarios were typed four or five to a page with page order randomized for each participant. In addition, the first and last pages of each booklet contained filler scenarios that were not used in the analyses.

The recognition test consisted of a group of four alternatives for each of the 24 targets (see Table 1). The four alternatives were as follows: (1) the utterance that had appeared in the speech act version of a scenario-for example, I'm so sorry I ruined your shirt-and was verbatim for the speech act version, but had an incorrect meaning for the control version; (2) the utterance that had appeared in the control version of a scenario-for example, Ed is so sorry he ruined your shirt - and was verbatim for the control version, but had an incorrect meaning for the speech act version; (3) the speech act utterance rewritten to include the relevant speech act verb-for example, $I$ apologize for ruining your shirt - and was correct with regard to the speech act lure for the speech act version, but was incorrect with regard to the speech act lure for the control version; and (4) the control utterance rewritten to include the speech act verb for that set-for example, Ed apologizes for ruining your new shirt-and was correct with regard to the speech act lure for the control, but was incorrect with regard to the speech act lure for the speech act version.

Procedure. Participants were run in small groups. They were told that the purpose of the study was to examine perceptions of conversations and that they would read a series of situation descriptions and remarks made by people in these situations. They were not told about the memory test. Instead, they were told to read the materials carefully and rate each vignette on a 7-point scale ranging from 1 (extremely uninteresting) to 7 (extremely interesting). Participants read at their own pace, and all finished within $15 \mathrm{~min}$. After reading the scenarios, participants were given $5 \mathrm{~min}$ to recall as many states in the United States as they could. Finally, participants performed a forced choice recognition task for the final utterances in the scenarios that they had read earlier. For each of the 24 sets, participants were asked to indicate which of the four alternatives they had read earlier.

\section{Results}

In both experiments, a $2 \times 4 \times 4$ (scenario type: speech act vs. control $\times$ recognition test item $\times$ manipulation type) repeated measures ANOVA was conducted, followed by single degree of freedom contrasts. The results are summarized in Table 2.

Experiment 1. Overall, memory for the different recognition test items varied as a function of whether participants had read the speech act or the control version of a scenario $\left[F_{1}(3,159)=22.08, M S_{\mathrm{e}}=.014, p<\right.$ $\left..001 ; F_{2}(3,69)=8.20, M S_{\mathrm{e}}=.017, p<.001\right]$. The critical follow-up test focused on memory for the speech act lure. As expected, participants were far more likely to falsely recognize the speech act lure when they had read the speech act versions $(M=21.5 \%)$ than when they had read the control versions $(M=9 \%)\left[F_{1}(1,53)=44.26, M S_{\mathrm{e}}=\right.$ $\left..01, p<.001 ; F_{2}(1,23)=16.63, M S_{\mathrm{e}}=.012, p<.001\right]$. There was, however, a significant three-way manipulation type $\times$ scenario type $\times$ recognition test item interaction in the participants analysis $\left[F_{1}(9,477)=3.44, M S_{\mathrm{e}}=.083\right.$, $p<.001]$. Follow-up tests (with participants as the random variable) for the speech act lure were conducted separately for each of the four manipulation types. The effect was in the predicted direction - that is, higher recognition rates for the speech act version than for the control version-for each manipulation type and was significant $(p<.05)$ for all but the negating-the-speech-act manipulation. ${ }^{4}$ 
Table 2

Recognition Test Performance (\%) for Speech Act and Control Utterances for Experiments 1 and 2

\begin{tabular}{lcc}
\hline & \multicolumn{2}{c}{ Scenario Type } \\
\cline { 2 - 3 } Recognition Test Item & Speech Act & Control \\
\hline \multicolumn{1}{c}{ Experiment 1} & \\
Verbatim & 63.0 & 57.6 \\
Correct with speech act lure & 21.5 & 9.0 \\
Incorrect meaning & 11.4 & 20.2 \\
Incorrect meaning with lure & 4.2 & 13.1 \\
\multicolumn{1}{c}{ Experiment 2} & \\
Verbatim & 78.0 & 78.0 \\
Correct with speech act lure & 15.0 & 4.8 \\
Incorrect meaning & 5.8 & 12.1 \\
Incorrect meaning with lure & 1.2 & 4.7 \\
\hline
\end{tabular}

Experiment 2. The results were almost identical to those obtained in Experiment 1 . The scenario type $\times$ recognition test item interaction was again reliable $\left[F_{1}(3,162)=15.05\right.$, $M S_{\mathrm{e}}=.009, p<.001 ; F_{2}(3,21)=7.08, M S_{\mathrm{e}}=.015, p<$ .01]. Most important, participants were again more likely to falsely recognize the speech act lure when they had read the speech act versions $(M=15 \%)$ than when they had read the control versions $(M=4.8 \%)\left[F_{1}(1,54)=36.92, M S_{\mathrm{e}}=\right.$ $\left..008, p<.001 ; F_{2}(1,23)=13.07, M S_{\mathrm{e}}=.009, p<.001\right]$. There was a significant three-way manipulation type $\times$ scenario type $\times$ recognition test item interaction in the participants analysis $\left[F_{1}(9,486)=3.75, M S_{\mathrm{e}}=.079, p<\right.$ .001]. Identical to that for Experiment 1, the effect was in the predicted direction for all four manipulation types and was significant $(p<.05)$ for all but the negating-the-speech-act manipulation. ${ }^{5}$

\section{Discussion}

Overall, regardless of whether participants had read descriptions of conversation utterances (Experiment 1) or the utterances themselves (Experiment 2), they were more likely to falsely recognize lures containing speech act verbs after having read remarks that performed those speech acts than after having read the control versions. The effect appears to be robust because it occurred regardless of how the control versions were constructed. In addition, participants did not simply indiscriminately choose lures with the speech act verbs. Rather, participants incorrectly identified the speech act verb as being present only when they got the meaning correct and not when they recognized the wrong meaning. This difference occurred in both Experiment $1(M \mathrm{~s}=21.5 \%$ vs. $4.2 \%)\left[F_{1}(1,53)=\right.$ $96.41, M S_{\mathrm{e}}=.008, p<.001 ; F_{2}(1,23)=28.68, M S_{\mathrm{e}}=$ $.013, p<.001]$ and Experiment $2(M \mathrm{~s}=15 \%$ vs. $1.2 \%)$ $\left[F_{1}(1,54)=73.62, M S_{\mathrm{e}}=.007, p<.001 ; F_{2}(1,23)=\right.$ $\left.31.68, M S_{\mathrm{e}}=.007, p<.001\right]$.

In sum, these two experiments provide some initial support for the proposition that speech acts play an important role in memory for conversation utterances.

\section{EXPERIMENT 3}

Recognition tests are very sensitive to false memory effects, so a recall task was used in Experiment 3. If con- versation utterances are tagged with the relevant speech act verbs, as argued here, then participants should be more likely to falsely recall the speech act verb after having read the speech act version than after having read the control version. Such a finding would strengthen the case for the long-term representation of illocutionary force, and this tendency should vary as a function of the strategy participants adopt as they attempt to recall the utterances. If speech act verbs serve as quick indicators of a speaker's intention, they should be more likely to be recalled when people are trying to recall the gist of what someone has said. This is because a focus on gist should produce an emphasis on good-enough processing - an attempt to quickly perceive a speaker's intention. Hence, I expected the difference between the speech act and control versions to be quite large under a gist instructional set. This effect should also occur when people attempt to recall the exact wording, although the speech act-control difference should be lessened because many speech act verbs are not naturally used in conversation utterances. In Experiment 3, participants attempted to recall the target utterances under either gist recall instructions or verbatim instructions. I expected higher false recall of speech act verbs for the speech act versions than for the control versions. I also expected this effect to be larger under gist instructions than under verbatim instructions.

\section{Method}

Participants. Participants $(N=81)$ were students enrolled in introductory psychology classes at Ball State University who participated for partial course credit. All participants spoke English as their first language.

Materials. The scenarios were identical to those used in Experiment 2 .

Procedure. Participants were run in small groups. They were told that the purpose of the study was to examine impression formation and that they would read a series of situation descriptions and remarks made by people in those situations. They were to read the materials carefully and try to form impressions of the scenario interactants. Participants read at their own pace, and all finished within $15 \mathrm{~min}$. They were then given 5 min to recall as many states in the United States as they could, after which they performed the cued-recall task. This recall task consisted of a set of 24 recall prompts consisting of two or three sentences from each of the 24 target scenarios. The recall prompts were the same for both the control and speech act scenarios. Participants were instructed to read the prompt and attempt to recall the final utterance for each of the 24 scenarios. Participants were randomly assigned to receive either the verbatim instructions or the gist instructions. For the former, participants were instructed to recall the exact wording of the remarks. For the latter, participants were told to write down the gist of what the speaker had said.

\section{Results and Discussion}

Recall protocols were coded for whether the speech act verb was included; the dependent measure was the percentage of scenarios for which the relevant speech act verb was part of the recalled utterance. The data are displayed in Figure 1.

There were reliable effects for both scenario type $\left[F_{1}(1,79)=49.09, M S_{\mathrm{e}}=.033, p<.001 ; F_{2}(1,23)=\right.$ $\left.29.34, M S_{\mathrm{e}}=.014, p<.001\right]$ and recall instructions $\left[F_{1}(1,79)=34.65, M S_{\mathrm{e}}=.036, p<.001 ; F_{2}(1,23)=\right.$ $\left.22.39, M S_{\mathrm{e}}=.013, p<.001\right]$. Participants were more 
likely to falsely recall the speech act verb in the speech act version $(M=16.3 \%)$ than in the control version $(M=$ $3.3 \%)$ and under gist instructions $(M=15.3 \%)$ than under verbatim instructions $(M=4.3 \%)$.

As expected, there was a reliable scenario type $\times$ recall instructions interaction $\left[F_{1}(1,79)=15.17, M S_{\mathrm{e}}=.033\right.$, $\left.p<.001 ; F_{2}(1,23)=24.99, M S_{\mathrm{e}}=.004, p<.001\right]$. As can be seen in Figure 1, the effect of the speech act manipulation was greater in the gist condition than in the verbatim condition. Follow-up simple effects tests, however, indicated that the speech act effect was reliable in both the verbatim condition and the gist condition (all $p \mathrm{~s}<.01$ ).

There was a significant scenario type $\times$ manipulation type interaction in the participants analysis $\left[F_{1}(3,237)=\right.$ $\left.5.5, M S_{\mathrm{e}}=.02, p<.001\right]$. Follow-up tests were conducted for each of the four types of scenario manipulation. The effect (i.e., higher false recall rates for the speech act verbs for the speech act versions than the control versions) was in the predicted direction for all manipulations and was significant $(p<.05)$ for three of them; it was marginally significant for the negating-the-speech-act manipulation $(p=.10)$.

Participants in this experiment were significantly more likely to falsely recall speech act verbs after having read the speech act version than after having read the control version. Hence, using recall rather than recognition, we found that the results of Experiment 3 replicate the results of Experiments 1 and 2. As in Experiments 1 and 2, the results in this experiment were consistent over the different types of controls. In short, the results of the first three experiments demonstrate-via memory errors—retention of speech act force in memory.

An additional finding in this study was the relatively larger speech act effect when participants were instructed

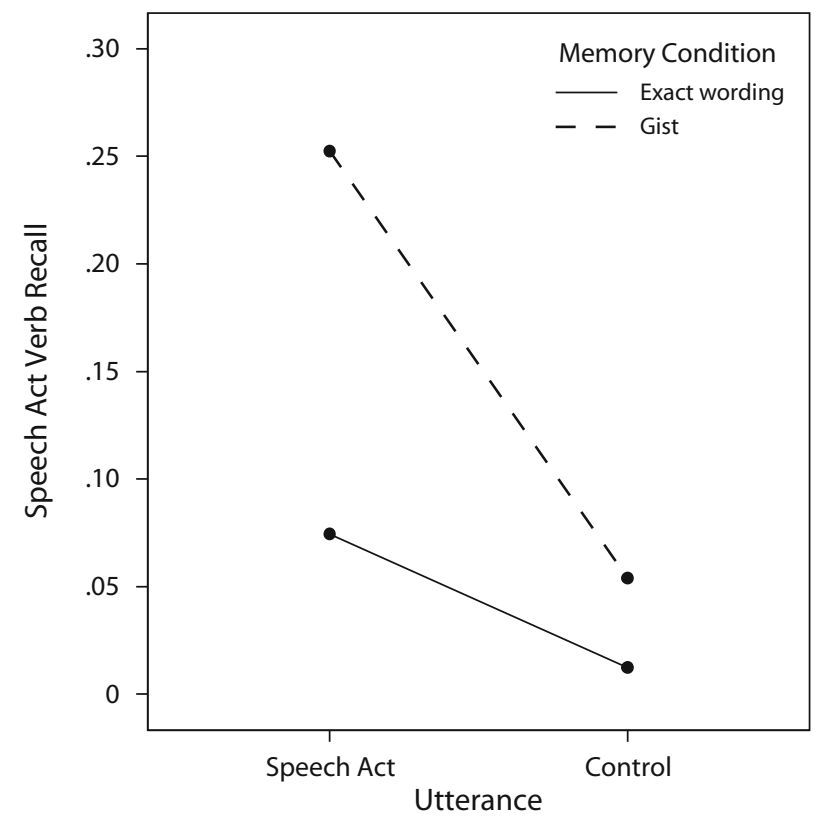

Figure 1. Percentage recalling speech act verbs for speech act and control versions under different recall instructions. to focus on gist. This makes sense because a focus on gist should result in an attempt to construct a summary representation that captures the essential details of a turn. Speech act verbs are made to order in this regard. Hence, these results support the idea that illocutionary force is a critical feature of memory for the gist of conversation remarks.

\section{EXPERIMENT 4}

Experiments 1 through 3 demonstrated a tendency for people to falsely remember speech act verbs when those verbs characterized the target utterance. These findings support the idea that the speech act verb is stored as an utterance tag that then influences the recognition (Experiments 1 and 2) or reconstruction (Experiment 3) of the to-be-remembered utterance. Experiment 4 was designed to test this in a different way. According to encoding specificity theory (Tulving, 1983; Tulving \& Thomson, 1973), a retrieval cue is effective to the extent that it matches information incorporated in the memory trace at the time of encoding. If the speech act performed with an utterance does form part of that representation, the speech act verb should serve as a good retrieval cue for the utterance. Participants in this experiment read the same conversation excerpts as those read in Experiments 1 through 3. Unlike those experiments, however, a cued recall procedure in which the relevant speech act verb served as the cue was used. On the basis of the results of Experiments 1 through 3, I expected that speech act cues would result in better memory for the speech act versions than for the control versions.

\section{Method}

Participants. Participants $(N=30)$ were students enrolled in introductory psychology classes at Ball State University who participated for partial course credit. All participants spoke English as their first language.

Materials. The scenarios were identical to those used in Experiments 2 and 3 .

Procedure. The procedure was identical to that in Experiment 2, except for the memory test. For the memory test, participants were given a numbered list containing the name of the speaker who had produced the final utterance in each scenario and a word (the speech act) that was described as being a word that could characterize that final remark. Participants were instructed to recall the utterance for each scenario. It was emphasized to participants that they were to recall the exact wording of each remark and not simply to paraphrase it.

\section{Results and Discussion}

Recall protocols were independently coded by two coders (blind to conditions). Each response was coded as blank (nothing recalled), verbatim recall, gist correct with critical keywords, or incorrect recall. To be coded as gist correct, participants had to recall not just the gist of the utterance, but critical keywords as well. This criterion was adopted to ensure that participants were indeed recalling the utterance and not simply reconstructing an utterance based on the presented cue-for example, making up an utterance that performs an apology when the cue was apologize. For example, if the target utterance had been I like your/her new coat, then any recalled utterance that could plausibly function as a compliment of a coat (e.g., Your new coat looks great, etc.) would be coded as cor- 
rectly recalling the gist. However, if a critical keyword (coat, in this example) was not included (e.g., I really like $i t$ ), the item would not be coded as correct gist recall. The overall coding agreement rate was $85.6 \%$, and all discrepancies were resolved via discussion. Because verbatim recall was very infrequent (less than $1.5 \%$ ), verbatim and correct gist recall were combined to create a measure of accurate utterance memory.

As expected, there was a reliable effect for the scenario type $\left[F_{1}(1,29)=5.19, M S_{\mathrm{e}}=.14, p<.03 ; F_{2}(1,23)=\right.$ $\left.8.73, M S_{\mathrm{e}}=.087, p<.01\right]$; participants were more likely to correctly recall the utterance when the cue represented the speech act performed with the target utterance $(M=$ $22.8 \%)$ than when it $\operatorname{did} \operatorname{not}(M=15.8 \%)$. This effect was the same for all four manipulation types, and the scenario type $\times$ manipulation type interaction was not significant $\left[F_{1}(3,87)<1, M S_{\mathrm{e}}=.14 ; F_{2}(3,69)<1, M S_{\mathrm{e}}=.09\right]$.

Separate analyses were conducted to examine false recall of the relevant speech act verb when gist was correctly recalled. The overall rate of false recall was relatively low. Consistent with the results of Experiment 3, however, participants were significantly more likely to falsely recall the speech verb when they had read the speech version $(M=6.7 \%)$ than when they had read the control version $(M=1.7 \%)\left[F_{1}(1,29)=9.43, M S_{\mathrm{e}}=\right.$ $\left..048, p<.01 ; F_{2}(1,23)=6.0, M S_{\mathrm{e}}=.075, p<.05\right]$.

\section{EXPERIMENT 5}

The purpose of this experiment was to extend the analysis by (1) replicating the Experiment 4 recall memory results; (2) demonstrating that the effect shown by those results was not due to the speech act versions' being more memorable than the control versions; and (3) examining individual differences in memory for speech acts. The procedure was the same as that for Experiment 4, except that the cues for half of the utterances were words that had literally been in the target utterance. For those instances in which speech act verbs served as the recall cue, I expected memory to be better for utterances performing the speech act than for the control utterances (consistent with Experiment 4). In contrast, when a literal word served as a cue, I did not expect a difference in memory as a function of whether the utterance did or did not perform a speech act. In other words, the literal word cue, unlike the speech act cue, should not be a more effective cue for the speech act utterance than for the control utterance. I also expected that because the literal cues were present in the utterance - rather than being inferred - they would be more effective recall cues than the speech act verbs.

To explore individual differences in memory, participants in this experiment completed the Conversation Indirectness Scale (CIS; Holtgraves, 1997b), a measure of the extent to which people interpret and produce indirect utterances. The CIS measures two separate dimensions. The dimension of interest here-termed an interpretation dimension - measures the extent to which a person looks for nonliteral or indirect meanings in others' communications. People scoring high on this dimension are relatively more likely to interpret others' utterances as conveying nonliteral meanings, and they are faster at recognizing these meanings (Holtgraves, 1997b). Illocutionary force represents an inference of sorts; it is not literally present in the utterance. People who score high on the interpretation dimension, and hence look for nonliteral meanings, should tend to characterize utterances in terms of their illocutionary force. Accordingly, speech act words should be significantly better cues for people who score high on the interpretation dimension of the CIS than for those who score low.

\section{Method}

Participants. Participants $(N=115)$ were students enrolled in introductory psychology classes at Ball State University who participated for partial course credit. All participants spoke English as their first language.

Materials. The scenarios were the same as those used in Experiments 2 through 4 .

Procedure. The procedure was identical to that used in Experiment 4, but with two exceptions. First, two recall memory booklets were constructed. Each booklet contained 12 cues representing the speech act performed with the final utterance (for the speech act scenarios) and 12 cues representing literal words (see the Appendix) that had been in the final utterance. The two booklets were mirror images, so that the speech act cues in one version were replaced with the literal cues in the other version. Second, after completing the cued-recall test, participants completed the 19-item CIS.

\section{Results and Discussion}

Recall protocols were independently coded by the same two coders (who were blind to conditions) who had coded the Experiment 4 protocols. The primary dependent measure was the percentage of utterances recalled correctly (either verbatim or gist with keyword). Participants' responses on the CIS interpretation scale were trichotomized into three groups (high, medium, and low).

There was a significant cue type $\times$ scenario type interaction $\left[F_{1}(1,113)=5.04, M S_{\mathrm{e}}=.024, p<.05 ; F_{2}(1,69)=\right.$ $\left.5.02, M S_{\mathrm{e}}=.013 p<.05\right]$. Simple effects tests indicated that, as expected, the speech act versions were more likely to be recalled than the control versions when speech act cues were used $(M \mathrm{~s}=28.4 \%$ vs. $20.1 \%)\left[F_{1}(1,113)=\right.$ $12.91, M S_{\mathrm{e}}=.03, p<.001 ; F_{2}(1,69)=15.16, M S_{\mathrm{e}}=$ $.013, p<.001]$, but not when literal cues were used $(M \mathrm{~s}=42.7 \%$ vs. $41.0 \%)\left[F_{1}(1,113)<1, M S_{\mathrm{e}}=.039\right.$; $\left.F_{2}(1,69)<1, M S_{\mathrm{e}}=.018\right]$. The scenario type $\times$ manipulation type interaction (for speech act cues only) was not significant $\left[F_{1}(3,226)<1, M S_{\mathrm{e}}=.14\right]$.

There were also significant main effects for cue type $\left[F_{1}(1,113)=128.37, M S_{\mathrm{e}}=.027, p<.001 ; F_{2}(1,69)=\right.$ $\left.21.47, M S_{\mathrm{e}}=.10, p<.001\right]$ - literal cues $(M=41.9 \%)$ were more effective, overall, than the speech act cues $(M=24.3 \%)$ - and scenario type $\left[F_{1}(1,113)=6.27\right.$, $M S_{\mathrm{e}}=.045, p<.05 ; F_{2}(1,69)=7.66, M S_{\mathrm{e}}=.019, p<$ $.05]$. However, as the simple effects tests above indicate, utterances from speech act scenarios were recalled better than utterances from the control utterances when the cue was a speech act word, not when it was a literal word.

Separate analyses were conducted to examine false recall of the relevant speech act verb (when gist was correctly recalled). Participants were significantly more likely to falsely recall the speech verb when they had read 
the speech act version $(M=5.3 \%)$ than when they had read the control version $(M=1.6 \%)\left[F_{1}(1,113)=30.36\right.$, $M S_{\mathrm{e}}=.005, p<.001 ; F_{2}(1,69)=10.04, M S_{\mathrm{e}}=.009, p<$ $.01]$. This effect was similar and was significant when the speech act was the cue $(M \mathrm{~s}=6.5 \%$ vs. $2.4 \%)\left[F_{1}(1,113)=\right.$ $13.21, M S_{\mathrm{e}}=.007, p<.001 ; F_{2}(1,69)=6.45, M S_{\mathrm{e}}=$ $.008, p<.01]$ and when a literal word served as the cue $(M \mathrm{~s}=4.1 \%$ vs. $0.9 \%)\left[F_{1}(1,113)=14.6, M S_{\mathrm{e}}=.004\right.$, $\left.p<.001 ; F_{2}(1,69)=7.27, M S_{\mathrm{e}}=.005, p<.01\right]$.

Individual differences. The main effect for the interpretation scale was not significant $\left[F_{1}(2,113)<1, M S_{\mathrm{e}}=\right.$ .097; $\left.F_{2}(2,69)<1, M S_{\mathrm{e}}=.124\right]$; overall memory was roughly equal across the three groups. However, the interpretation scale did interact with scenario type $\left[F_{1}(2,113)=\right.$ $3.18, M S_{\mathrm{e}}=.045, p<.05 ; F_{2}(2,69)=2.89, M S_{\mathrm{e}}=.019$, $p<.06]$ and cue type $\left[F_{1}(2,113)=3.97, M S_{\mathrm{e}}=.027, p<\right.$ $.05]$ in the participants analysis, but not when items were treated as a random variable $\left[F_{2}(2,69)<1, M S_{\mathrm{e}}=.10\right]$. Participants scoring high on the interpretation scale displayed far better memory for the speech act versions $(M=39.7 \%)$ than for the control versions $(M=27.7 \%)\left[F_{1}(1,30)=\right.$ $10.04, M S_{\mathrm{e}}=.044, p<.01 ; F_{2}(1,23)=5.39, M S_{\mathrm{e}}=.011$, $p<.05]$, a difference that did not occur for those with moderate $(M \mathrm{~s}=31.6 \%$ vs. $32.2 \%)\left[F_{1}(1,40)<1, M S_{\mathrm{e}}=.043\right.$; $\left.F_{2}(1,23)<1, M S_{\mathrm{e}}=.01\right]$ or low $(M \mathrm{~s}=35.4 \%$ vs. $31.9 \%)$ $\left[F_{1}(4,44)=1.18, M S_{\mathrm{e}}=.047, p>.25 ; F_{2}(1,23)=3.69\right.$, $\left.M S_{\mathrm{e}}=.018, p>.05\right]$ scores on the interpretation scale (see Figure 2).

The literal cue was significantly more effective than the speech act cue regardless of CIS score (all $p s<.05$ ). However, as can be seen in Figure 3, the effectiveness of speech act cues increased, and the effectiveness of literal words decreased, as CIS scores increased.

Finally, separate analyses were conducted to examine false recall as a function of scores on the interpretation scale. In contrast with correct recall, CIS scores did not interact with either scenario type $\left[F_{1}(2,113)=1.76, M S_{\mathrm{e}}=\right.$ $\left..005, p>.10 ; F_{2}(2,69)<1, M S_{\mathrm{e}}=.009\right]$ or cue type $\left[F_{1}(2,113)<1, M S_{\mathrm{e}}=.006 ; F_{2}(2,69)<1, M S_{\mathrm{e}}=.004\right]$. In short, speech act cues had a more substantial effect on the correct-but not the incorrect-memory of people who scored high on the interpretation scale of the CIS.

\section{GENERAL DISCUSSION}

People typically participate in a wide range of verbal interactions during the course of a day. Many of these interactions are processed mindlessly (Kitayama \& Burnstein, 1988; Langer, Blank, \& Chanowitz, 1978), and little is remembered from them. But not all is forgotten. Memory for conversations is crucial for maintaining one's social relationships, performing one's job competently, and just getting along in life. But what exactly do people remember from those conversations? Occasionally, there may be verbatim memory for conversation remarks, especially when the wording of the remark is interpersonally important in some way (Holtgraves, 1997a; Keenan et al., 1977). More often, however, people will remember the gist of what was said. An important question, then, concerns the exact nature of this gist.

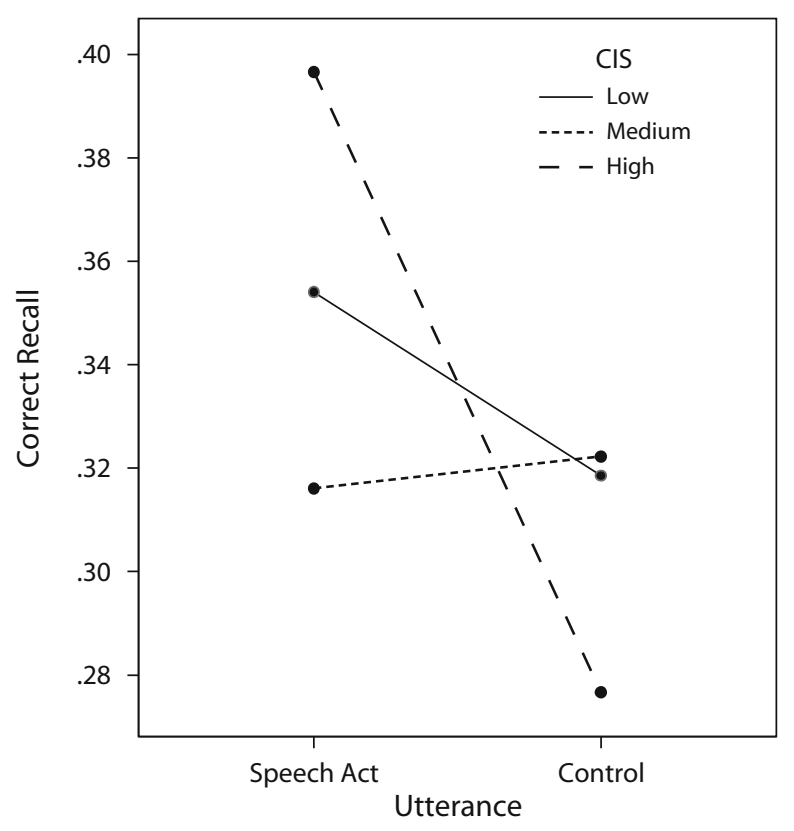

Figure 2. Correct utterance recall as a function of speech act type and Conversation Indirectness Scale (CIS) score.

There are two features of conversational interaction that should be influential in this regard. First, conversations are cognitively taxing activities that require participants to quickly alternate the speaker and hearer role, to simultaneously plan what to say and comprehend what their partner is saying. These demands make it unlikely that conversationalists will completely process each and every turn. Rather, conversation processing should be oriented toward some type of good-enough processing — a quick

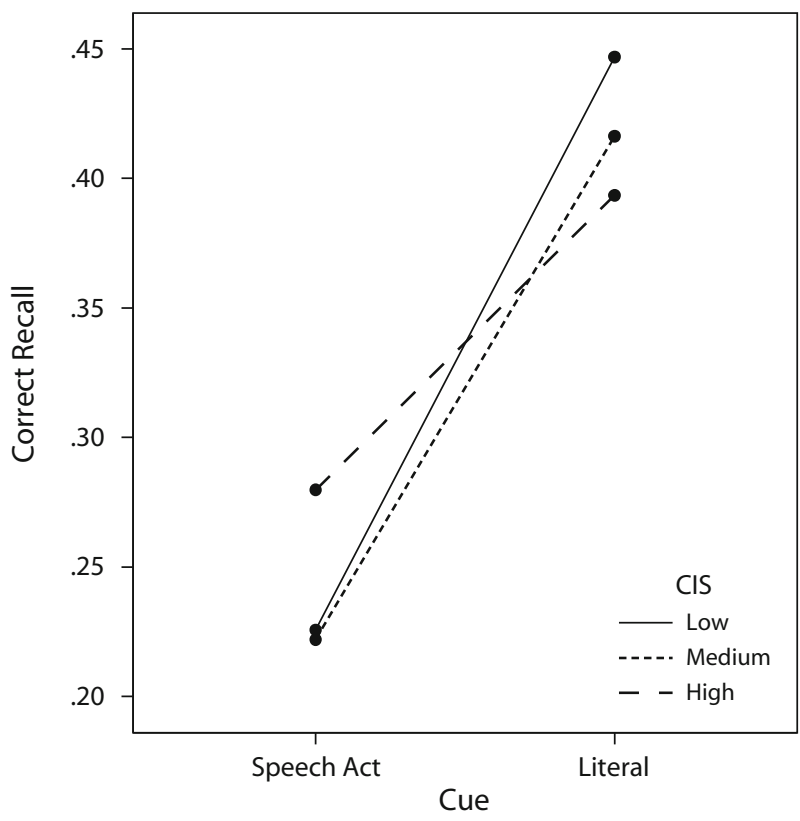

Figure 3. Correct utterance recall as a function of cue type and Conversation Indirectness Scale (CIS) score. 
and serviceable snapshot of a conversational turn. Second, conversation utterances are intentional acts, and most theories of conversation (see, e.g., Austin, 1962; Cohen \& Perrault, 1979; Gibbs, 1999, 2003; Grice, 1957; Searle, 1969, 1979; Sperber \& Wilson, 1986, 1995, 2002; Stone, 2005) assume that hearers attempt to recognize the speaker's intention in producing a particular utterance. In sum, what people remember from a conversation turn needs to be both short and based on the speaker's intention.

Although there is wide agreement regarding the importance of intention recognition in conversation processing, there is disagreement on the nature of that recognition. Fundamental to speech act theory (Searle, 1969) is the notion that people categorize utterances in terms of the speech act performed; that is, recognition of illocutionary force is entailed in comprehension. Note that speech act recognition satisfies both of the above requirements; it captures with a single word (good-enough processing) the intended action performed by the speaker. Relevance theory (Sperber \& Wilson, 1995) and certain computation models explicitly deny the necessity of this step. In this view, speech act categorization is possible after the fact, but is not a necessary component of comprehension.

Consistent with previous research demonstrating the role played by speech act recognition in comprehension (Holtgraves, 2007, in press; Holtgraves \& Ashley, 2001), the present experiments demonstrate a role played by speech act recognition in long-term memory. Participants in Experiments 1 through 3 tended to falsely recognize (Experiments 1 and 2) or falsely recall (Experiment 3 ) speech acts characterizing utterances that they had read earlier. This was more likely to happen when they attempted to recall the gist, rather than the exact wording, although it happened in both types of recall - a finding consistent with the view that illocutionary force represents a quick and serviceable perception of a speaker's intention.

Experiments 4 and 5 provided additional evidence that speech acts are stored as utterance tags. In these experiments, speech act verbs served as retrieval cues for the recall of conversation utterances; when speech act verbs were provided as cues, participants were more likely to recall the associated utterance than the control utterance. In the present studies, memory for utterances that performed specific speech acts was compared with memory for very similar utterances that did not perform those speech acts (control utterances). That the control versions differed in so many ways and yet yielded such consistent effects suggests fairly strongly that it was the activation of the target speech act that produced the differences observed in these experiments. Finally, not everyone processes conversations in the same way. Some people tend to look for indirect meanings and generate many conversational inferences; others are less likely to do so (Holtgraves, 1997b). In Experiment 5, the memory of participants scoring high on the CIS was more influenced by speech act verbs than was the memory of those scoring low on the CIS.

The present research has both theoretical and practical significance. In past research, gist has typically referred to anything that is extracted from a sentence or utterance at the time of encoding. Obviously, this is vague and fairly open ended. Hence, the speech act concept provides a mechanism for defining gist with more precision. At the same time, this should not be taken as meaning that speech acts exhaust the gist of an utterance. For one thing, not every utterance performs a speech act. For another, speech acts alone fail to capture some of the interpersonal aspects of language that may be retained as part of the gist (see, e.g., Holtgraves, 1997a).

Theoretical significance also derives from the fact that many psychological phenomena involve interpersonal (i.e., conversational) as well as intrapersonal processes. Hence, what sometimes appears to be the output of an intrapersonal process - for example, the operation of the representativeness heuristic - may be the result of an interpersonal process, such as the operation of conversational rules (see, e.g., Hilton, 1995; Schwarz, 1996). Consider the processes involved in person perception. Many times, impressions of others are formed during conversations with them. That is, conversations are the raw social stimuli for impression formation. To the extent that impressions are not formed online (Hastie \& Park, 1986; Wyer, 2004), conversation memory - especially speech act memory-may serve as the basis for these impressions. Someone who is remembered as issuing a relatively high number of directives will probably be perceived as being relatively high in status (see, e.g., Wish, D'Andrade, $\&$ Goodenough, 1980). Note, however, that conversation memory and social processes are intimately intertwined: Interlocutors may perceive another's utterance as a directive because he or she has high status, rather than perceiving him or her as having high status due to the number of issued directives (Holtgraves et al., 1989).

One of the areas for which conversation memory has clear practical implications is in legal contexts. Court proceedings frequently involve testimony of what a witness remembers from a specific conversation, including who said what to whom in what context. Yet empirical research that explicitly examines the factors that influence conversation memory is lacking (see Davis \& Friedman, 2005). The tendency to misremember the occurrence of speech act verbs, as demonstrated in the present research, has obvious implications for courtroom testimony. A witness might recall a person's utterance as a warning even though the performative verb warn had not been part of the utterance. Another area of clear practical significance involves what people remember from conversations with their physicians. One of the major findings in this area is that individuals' memory for these conversations is extremely poor (e.g., Ley, 1979). Although there are many factors influencing memory in this situation, the use of explicit performative verbs (e.g., I'm warning you ..., I'm demanding that you . . , and so on) would no doubt lessen ambiguity and improve memory for the illocutionary force of a physician's utterances.

As important as speech acts are, recognizing and remembering a speaker's speech acts is not at all straightforward. One of the limitations of the present approach (as well as of speech act theory in general) is the focus on a single conversational turn as the unit of analysis. This is problematic because speech acts can sometimes be performed over a series of turns, as when interlocutors check on various preconditions for performing a speech act and then clarify 
their intentions when queried about them (Holtgraves, 2002). In these instances, recognition of the speaker's intention and of the long-term representation of that intention becomes more complex. Also, speech act theory, to a large extent, ignores the interpersonal underpinnings of language use. Why, for example, do people rarely use performative verbs? Are there certain situations in which they are more likely to be used? Understanding how people use language to accomplish their goals will necessarily involve a consideration of the interpersonal processes involved in language use (see, e.g., Holtgraves, 1998).

Second, the speech act a speaker intends might not be the speech act recognized by the recipient. This is because speakers may not always have clear, well-formulated intentions; sometimes intentions are emergent and are negotiated during the course of a conversation (Gibbs, 1999). And when people do have clear intentions, they do not always use explicit performatives; in fact, they rarely do so. Moreover, sometimes speakers do not want the recipient to recognize the speech act being performed. A speaker who wants to brag, for example, probably does not want the recipient to recognize that she is bragging. Thus, misunderstandings invariably occur. For example, in the research conducted to develop the materials used in this research (Holtgraves, 2005a), participants' recognition of the implicit speech acts that other participants intended to perform with utterances was far from perfect. In general, people believe they are more successful at their communications than they objectively are (Keysar \& Henley, 2002). In fact, research has demonstrated that speakers and hearers systematically diverge in their interpretations of indirect replies (Holtgraves, $2005 b)$. What is critical for conversation memory is the recipient's recognition of a particular speech act, and this speech act need not necessarily be the one the speaker intends to have recognized. In short, speech acts cannot simply be equated with the speaker's intentions.

Finally, the materials used in the present studies were conversations read by participants who were observers, not by actual conversation participants. Hence, there is the issue of whether the present results would generalize to people involved in actual conversations. Two things should be kept in mind in this regard. First, the present studies probably underestimated the extent to which conversationalists engage in heuristic processing. This is because participants in the present studies were allowed to read the conversation with no time constraints and hence to engage in deeper processing than people who are involved in an actual conversation. Second, in my research on speech act comprehension (Holtgraves, in press), I have attempted to assess speech act comprehension with conversation (i.e., chat) participants, as well as with observers. I have found automatic speech act comprehension in both situations. Still, there is no doubt that it would be worthwhile to pursue the issue of the generalizability of the present findings.

In conclusion, my recognition of others' intentions is a critical component of being a competent social being; it is at the heart of a "theory of mind" (Leslie, 1987). Recognition of speech acts is a very specific manifestation of this ability in normal language users. The present research suggests that speech act representation is also an important organizational feature of conversation memory.

\section{AUTHOR NOTE}

This research was supported by National Science Foundation Grant 0131877. Correspondence concerning this article should be addressed to T. Holtgraves, Department of Psychological Science, Ball State University, North Quad 108B, Muncie, IN 47306 (e-mail: 00t0holtgrav@bsu.edu).

\section{REFERENCES}

ACKerman, B. P. (1982). Contextual integration and utterance interpretation: The ability of children and adults to interpret sarcastic utterances. Child Development, 53, 1075-1083.

Allen, J. (1983). Recognizing intentions from natural language utterances. In M. Brady \& R. C. Berwick (Eds.), Computational models of discourse (pp. 107-166). Cambridge, MA: MIT Press.

Austin, J. L. (1962). How to do things with words. Oxford: Oxford University Press.

Bransford, J. D., \& Franks, J. J. (1971). The abstraction of linguistic ideas. Cognitive Psychology, 2, 331-350.

BREWER, W. F. (1977). Memory for the pragmatic implications of sentences. Memory \& Cognition, 5, 673-678.

Clark, H. H. (1996). Using language. Cambridge: Cambridge University Press.

Clark, H. H., \& Wilkes-GibBs, D. (1986). Referring as a collaborative process. Cognition, 22, 1-39.

Cohen, P. R., \& Levesque, H. J. (1990). Rational interaction as the basis for communication. In P. R. Cohen, J. Morgan, \& M. E. Pollack (Eds.), Intentions in communication (pp. 221-256). Cambridge, MA: MIT Press.

Cohen, P. R., \& Perrault, C. R. (1979). Elements of a plan-based theory of speech acts. Cognitive Science, 3, 177-212.

Dascal, M. (1987). Defending literal meaning. Cognitive Science, 11, 259-281.

DAVIS, D., \& Friedman, R. D. (2005). Memory for conversation: The orphan child of witness memory researchers. In M. P. Toglia, J. D. Read, D. F. Ross, \& R. C. L. Lindsay (Eds.), Handbook of eyewitness psychology: Vol. 1. Memory for events (pp. 3-52). Mahwah, NJ: Erlbaum.

Ferreira, F., Bailey, K. G. D., \& Ferraro, V. (2002). Good-enough representations in language comprehension. Current Directions in Psychological Science, 11, 11-15.

Ferreira, F., \& Clifton, C., JR. (1986). The independence of syntactic processing. Journal of Memory \& Language, 25, 348-368.

GiBBS, R. W., JR. (1984). Literal meaning and psychological theory. Cognitive Science, $8,275-304$.

GIBBS, R. W., JR. (1999). Intentions in the experience of meaning. Cambridge: Cambridge University Press.

GiBBS, R. W., JR. (2003). Nonliteral speech acts in text and discourse. In A. C. Graesser, M. A. Gernsbacher, \& S. R. Goldman (Eds.), Handbook of discourse processes (pp. 357-393). Mahwah, NJ: Erlbaum.

Grice, H. P. (1957). Meaning. Philosophical Review, 66, 377-388.

Grice, H. P. (1975). Logic and conversation. In P. Cole \& J. Morgan (Eds.), Syntax and semantics: Vol. 3. Speech acts (pp. 41-58). New York: Academic Press.

HAstie, R., \& PARK, B. (1986). The relationship between memory and judgment depends on whether the judgment task is memory-based or on-line. Psychological Review, 93, 258-268.

Hermans, H. J. M. (1996). Voicing the self: From information processing to dialogical interchange. Psychological Bulletin, 119, 31-50.

Hilton, D. J. (1995). The social context of reasoning: Conversational inference and rational judgment. Psychological Bulletin, 118, 248-271.

Holtgraves, T. (1997a). Politeness and memory for the wording of remarks. Memory \& Cognition, 25, 106-116.

Holtgraves, T. (1997b). Styles of language use: Individual and cultural variability in conversational indirectness. Journal of Personality \& Social Psychology, 73, 624-637.

Holtgraves, T. (1998). Interpreting indirect replies. Cognitive Psychology, 37, 1-27. 
Holtgraves, T. M. (2002). Language as social action: Social psychology and language use. Mahwah, NJ: Erlbaum.

Holtgraves, T. (2005a). The production and perception of implicit performatives. Journal of Pragmatics, 37, 2024-2043.

Holtgraves, T. (2005b). Diverging interpretations associated with the perspectives of the speaker and recipient in conversations. Journal of Memory \& Language, 53, 551-566.

Holtgraves, T. (2007). Second language learners and speech act comprehension. Language Learning, 57, 595-610.

Holtgraves, T. (in press). Automatic intention recognition in conversation processing. Journal of Memory \& Language.

Holtgraves, T., \& Ashley, A. (2001). Comprehending illocutionary force. Memory \& Cognition, 29, 83-90.

Holtgraves, T., Srull, T. K., \& Socall, D. (1989). Conversation memory: The effects of speaker status on memory for the assertiveness of conversation remarks. Journal of Personality \& Social Psychology, 56, 149-160.

JaRvella, R. J., \& Collas, J. G. (1974). Memory for the intentions of sentences. Memory \& Cognition, 2, 185-188.

Keenan, J. M., MacWhinney, B., \& Mayhew, D. (1977). Pragmatics in memory: A study of natural conversation. Journal of Verbal Learning \& Verbal Behavior, 16, 549-560.

Kemper, S. (1980). Memory for the form and force of declaratives and interrogatives. Memory \& Cognition, 8, 367-371.

Keysar, B., \& Henley, A. S. (2002). Speakers' overestimation of their effectiveness. Psychological Science, 13, 207-212.

Kintsch, W., \& Bates, E. (1977). Recognition memory for sentences from a classroom lecture. Journal of Experimental Psychology: Human Learning \& Memory, 3, 150-159.

Kitayama, S., \& Burnstein, E. (1988). Automaticity in conversations: A reexamination of the mindlessness hypothesis. Journal of Personality \& Social Psychology, 54, 219-224.

KLAUER, K. C., \& WEGENER, I. (1998). Unraveling social categorization in the "Who said what?" paradigm. Journal of Personality \& Social Psychology, 75, 1155-1178.

Langer, E. J., Blank, A., \& Chanowitz, B. (1978). The mindlessness of ostensibly thoughtful action: The role of "placebic" information in interpersonal interaction. Journal of Personality \& Social Psychology, 36, 635-642.

LESLIE, A. M. (1987). Pretense and representation: The origins of "theory of mind." Psychological Review, 94, 412-426.

LEY, P. (1979). Memory for medical information. British Journal of Social \& Clinical Psychology, 18, 245-255.

MacWhinney, B., Keenan, J., \& Reinke, R. (1982). The role of arousal in memory for conversation. Memory \& Cognition, 10, 308-317.

Miller, J. B., DeWinstanley, P. [A.], \& Carey, P. (1996). Memory for conversation. Memory, 4, 615-631.

Murphy, G. L., \& Shapiro, A. M. (1994). Forgetting of verbatim information in discourse. Memory \& Cognition, 22, 85-94.

SACHS, J. S. (1967). Recognition memory for the syntactic and semantic aspects of connected discourse. Perception \& Psychophysics, 2, 437-442.

SACHS, J. S. (1974). Memory in reading and listening to discourse. Memory \& Cognition, 2, 95-100.

SAnford, A. J., \& Graesser, A. C. (2006). Shallow processing and underspecification. Discourse Processes, 42, 99-108.

Schwarz, N. (1996). Cognition and communication: Judgmental biases, research methods, and the logic of conversation. Mahwah, NJ: Erlbaum.

Schweller, K. G., Brewer, W. F., \& Dahl, D. A. (1976). Memory for illocutionary forces and perlocutionary effects of utterances. Journal of Verbal Learning \& Verbal Behavior, 15, 325-337.

Searle, J. R. (1969). Speech acts: An essay in the philosophy of language. Cambridge: Cambridge University Press.

SEARLE, J. R. (1979). Expression and meaning: Studies in the theory of speech acts. Cambridge: Cambridge University Press.

SEarle, J. R., \& VanderVeKen, D. (1985). Foundations of illocutionary logic. Cambridge: Cambridge University Press.

Sperber, D., \& Wilson, D. (1986). Relevance: Communication and cognition. Oxford: Blackwell.

Sperber, D., \& Wilson, D. (1995). Relevance: Communication and cognition (2nd ed.). Oxford: Blackwell.
Sperber, D., \& Wilson, D. (2002). Pragmatics, modularity and mindreading. Mind \& Language, 17, 3-23.

Stone, M. (2005). Communicative intentions and conversational processes in human-human and human-computer dialogue. In J. C. Trueswell \& M. K. Tanenhaus (Eds.), Approaches to studying world-situated language use: Bridging the language-as-product and language-as-action traditions (pp. 39-69). Cambridge, MA: MIT Press.

Taylor, S. E., Fiske, S. T., Etcoff, N. L., \& Ruderman, A. J. (1978). Categorical and contextual bases of person memory and stereotyping. Journal of Personality \& Social Psychology, 36, 778-793.

Tulving, E. (1983). Elements of episodic memory. Oxford: Oxford University Press, Clarendon Press.

Tulving, E., \& Thomson, D. M. (1973). Encoding specificity and retrieval processes in episodic memory. Psychological Review, 80, 352-373.

VAnderveken, D. (1990). Meaning and speech acts: Vol. I. Principles of language use. Cambridge: Cambridge University Press.

VAN DiJK, T. A., \& KINTSCH, W. (1983). Strategies in discourse comprehension. New York: Academic Press.

WANNER, E. (1974). On remembering, forgetting, and understanding sentences: A study of the deep structure hypothesis. The Hague: Mouton.

Wish, M., D’Andrade, R. G., \& Goodenough, J. E. (1980). Dimensions of interpersonal communication: Correspondences between structures for speech acts and bipolar scales. Journal of Personality \& Social Psychology, 39, 848-860.

WYER, R. S., JR. (2004). Social comprehension and judgment: The role of situation models, narratives, and implicit theories. Mahwah, NJ: Erlbaum.

Wyer, R. S., Budesheim, T. L., Lambert, A. J., \& Swan, S. (1994). Person memory and judgment: Pragmatic influences on impressions formed in a social context. Journal of Personality \& Social Psychology, 66, 254-267.

ZWAAN, R. A., \& RADVANSKY, G. A. (1998). Situation models in language comprehension and memory. Psychological Bulletin, 123, 162-185.

\section{NOTES}

1. Note that the illocutionary force (or speech act) is not the same as the illocutionary point of an utterance. The latter is a high-level organizing scheme based on the direction of fit between one's words and the world and includes five categories (directive, assertive, commissive, expressive, declarative). Within each of these five illocutionary points are more specific illocutionary acts (e.g., warn, thank, brag, beg, etc.) that capture the specific intentional action the speaker is performing with the utterance (see Searle \& Vanderveken, 1985).

2. I use this terminology rather than the distinction between direct and indirect speech acts in order to avoid some of the controversy surrounding that distinction (e.g., Dascal, 1987; Gibbs, 1984). I simply define all explicit speech acts as those containing the performative verb and all implicit speech acts as those not containing the performative verb.

3 . Although $38 \%$ may seem rather low, keep in mind that the provided word had to be exact - that is, if the speech act was accuse, then blame was not accepted.

4. The other speech act-control differences that were significant were as follows: First, verbatim memory was better for the speech act version $(M=63 \%)$ than for the control version $(M=57.6 \%)$, an effect that was significant over participants $\left[F_{1}(1,53)=6.12, M S_{\mathrm{e}}=.013, p<\right.$ $.02]$, but not over items $\left[F_{2}(1,23)=1.36, M S_{\mathrm{e}}=.024, p>.25\right]$. For the other two recognition test items, recognition rates were higher for the control version than the speech act version [for meaning shift alternatives, $F_{1}(1,53)=21.14, M S_{\mathrm{e}}=.01, p<.001 ; F_{2}(1,23)=8.34, M S_{\mathrm{e}}=$ $.012, p<.01$; for meaning shift alternatives containing the speech act verb, $F_{1}(1,53)=22.35, M S_{\mathrm{e}}=.01, p<.001 ; F_{2}(1,23)=25.1, M S_{\mathrm{e}}=$ $.044, p<.001]$.

5. Unlike in Experiment 1, verbatim memory was roughly the same for the speech act and control versions. As in Experiment 1, recognition rates for the remaining two recognition test items were higher in the control version than in the speech act version [for meaning shift alternatives, $F_{1}(1,54)=18.06, M S_{\mathrm{e}}=.006, p<.001 ; F_{2}(1,23)=4.52, M S_{\mathrm{e}}=.011$, $p<.05$; for meaning shift alternatives containing the speech act verb, $F_{1}(1,54)=10.11, M S_{\mathrm{e}}=.003, p<.01 ; F_{2}(1,23)=11.5, M S_{\mathrm{e}}=.001$, $p<.01]$. 


\section{APPENDIX}

Speech act verbs are presented first, followed by the literal cue. The control versions of the scenarios were created by substituting the italicized material for the material in parentheses.

1. Agree-experiment. Andy and Bob are friends who frequently discuss current topics. One day, during a discussion of animal rights, they have the following exchange:

(Andy: "I don't think animals should be used in medical experiments."

Bob: "You're right. It's wrong to experiment on animals.")

Andy: "I heard you don't think animals should be used in medical experiments."

Bob: "That's right. It's wrong to experiment on animals."

2. Offer-call. Andrew's older cousin Bob recently purchased a small house. Now the process of moving is about to begin.

(Bob has helped Andrew in the past and so when Andrew hears of Bob's upcoming move he says to him,

Andrew: "If you need some help, just give me a call.")

Bob refused to help Andrew in the past and so when Andrew hears of Bob's upcoming move, he says to him,

Andrew: "If you need some help, don't give me a call."

3. Demand-bank. Cheryl's bank makes an error in her checking account. This error results in a check that she wrote being returned for insufficient funds. It is clearly the bank's fault and they admit that this is the case.

(Cheryl asked a bank representative to pay for the canceled check fee but she said the bank could not do that.

Cheryl strongly believes that they should do this.

So, she called the bank manager and said to him,

Cheryl: "The bank must pay for the fee.")

Cheryl asked a bank representative to pay for the canceled check fee and she said the bank could do that.

Cheryl was very happy that they would do this.

So, she called the bank manager and said to him,

Cheryl: "I'm so happy the bank will pay for the fee."

4. Thank-help. James recently decided to move to a new house. He had lots of stuff to move and a good friend of his, Kevin, graciously agreed to help with the move. Kevin worked all day helping James move.

(At the end of the day the following exchange took place,

Kevin: "Well, I guess that's it."

James: "I appreciate your help so much. I couldn't have done it without you.")

The next day Mark asked Kevin about his helping James move.

Mark: "I heard you helped James move yesterday."

Kevin: "He appreciated my help so much. He couldn't have done it without me."

5. Deny-CDs. Cody and Adam are roommates.

(One day, Cody accused Adam of taking several of his favorite CDs without asking.

Cody: "You took my CDs, didn't you?"

Adam: "No, I did not take your CDs.")

Cody wondered whether he had returned to Adam some CDs he had borrowed.

Cody: "I returned your CDs, didn't I?"

Adam: "No, you did not return my CDs."

6. Threaten-grounded. Paula was often responsible for watching her two younger brothers when her parents were gone. Her brothers usually got along well, but on occasion they would fight. This particular day, they seemed to get in a fight every five minutes.

(Paula was very tired of this and wanted them to stop.

She said to them,

Paula: "If you don't stop, I'll tell mom and dad and you'll be grounded.")

Paula's sister, Cheryl, was very tired of this and complained to Paula about it.

Paula said to Cheryl,

Paula: "If they don't stop, I'll tell mom and dad and they'll be grounded."

7. Apologize—-shirt. Dave and his brother Ron are close in age and size and often share each other's clothes. One day Dave borrowed a shirt from Ron. Unfortunately, Dave spilled oil-based paint on it and totally ruined it.

(Ron: "I think you ruined my shirt."

Dave: "I'm so sorry that I ruined your shirt.")

Ron complained about this to his other brother, Ed.

Ron: "I think Dave ruined my shirt."

Ed: "Dave's so sorry that he ruined your shirt."

8. Guess-\$100. Dennis just bought himself a new coat. When he wears it to work one day a coworker asks him how much it costs.

(Because it was a gift he doesn't know how much it cost and so he says,

Dennis: "I don't really know, but would estimate around \$100.")

Because he just bought it he knows exactly how much it cost and so he says,

Dennis: "I really do know, it was exactly $\$ 100 . "$

9. Brag-semester. Tom was talking about school with Vic, a close friend of his.

(At one point in their conversation Tom asks Vic how he did last semester.

Tom: "So, how was your semester?" 
Vic: "I did really good last semester, in fact I got a higher GPA than anyone else on my floor. I was super happy.") At one point in their conversation Tom asks Vic how Vic's roommate, Mark, did last semester.

Tom: "So, how was Mark's semester?"

Vic: "Mark did really good last semester, in fact he got a higher GPA than anyone on my floor. He was super happy."

10. Ask - time. Jane is late for class and doesn't have a watch.

(She needs to know the time.

So she approaches someone and says to them,

Jane: "What time is it?")

She needs to know if she has time to get a soda.

But her friend Nancy says to her,

Nancy: "It is time for class."

11. Beg-movie. There was this particular movie that Teresa wanted her parents to take her to see. All of her friends had seen it and she really wanted to see it too.

(She would do anything to see it.

Her parents, however, were not enthusiastic about taking her to see it.

Mom: "I don't think we're going to be able to go see it."

Teresa: "Please, please, please take me to the movie. I will do anything you want me to do.")

She would have done anything to see it.

Her parents, however, were not enthusiastic about taking her to see it.

And so they didn't go.

Teresa: "Please, please, please. Why didn't you take me to the movie? I would have done anything you wanted me to do."

12. Congratulate-happy.

(Robert's roommate, Andrew, is set on becoming a lawyer.

After applying to several law schools Andrew just received notice that he was accepted by his first choice.

When Robert finds out he says to Andrew,

Robert: "That's awesome. I'm so happy for you.")

Robert and Jim's roommate, Andrew, is set on becoming a lawyer.

After applying to several law schools Andrew just received notice that he was accepted by his first choice.

When Robert finds out he says to his roommate Jim,

Robert: "That's awesome. I'm so happy for Andrew."

13. Blame - fault. In one of her classes Laura worked with Mary on a group project. Unfortunately, they did very little of the work. As a result Laura did not get a very good grade in this class. Laura's parents wonder why she did so poorly in this course.

Dad: "Why did you do so poorly in your history class?"

(Laura: "It's Mary's fault.")

Laura: "It's nobody's fault."

14. Encourage- - stop.

(Vicky was trying to teach her younger sister, Yvonne, how to play a video game.

It was a difficult game and Yvonne was having a hard time.

Yvonne: "I'm not doing well and I want to quit."

Vicky: "Don't stop now. You can do it.")

Vicky was trying to teach her younger sisters, Yvonne and Carol, how to play a video game.

It was a difficult game and although Carol was doing well, Yvonne was having a hard time.

Carol: "She's not doing well and so I want to quit."

Vicky: "Don't stop now. She can do it."

15. Remind - dentist. Cheryl and Deborah have been close friends since grade school. Now they are rooming together at college. Deborah tends to be very forgetful.

(Today, Cheryl is sure Deborah doesn't remember her dentist appointment.

They are eating breakfast together when Cheryl says to Deborah,

Cheryl: "Did you know you have a dentist appointment today?")

Cheryl is sure Deborah had forgotten her dentist appointment today.

They are eating dinner together when Cheryl says to Deborah,

Cheryl: "I'll bet you forgot to go to your dentist appointment today."

16. Introduce - friend. Allan attended a party one weekend given by his good friend Brad.

(Allan brought along another friend of his, Charles, who hardly knew anyone at the party. He brought Charles over to Brad and said,

Allan: "Brad, this is my friend Charles.")

Allan brought along another friend of his, Charles, who knew everyone at the party. He brought Charles over to Brad and said,

Allan: "Brad, you remember my friend Charles."

17. Complain - tuition.

(The university that Ernest attends just raised tuition again. 
APPENDIX (Continued)

Ernest is upset about this and is talking with his friend Franklin and says to him,

Ernest: "I can't believe they raised tuition again. College just keeps on getting more and more expensive.")

The university that Ernest attends didn't raise tuition for a change.

Ernest is happy about this and is talking with his friend Franklin and says to him,

Ernest: "I can't believe they didn't raise tuition. College was just getting more and more expensive."

18. Compliment-coat. Gloria showed up at the office wearing a new coat.

(When her coworker Heather saw it she said to her,

Heather: "I like your new coat.")

When her coworker Heather saw it she said to her friend Stacy,

Heather: "I like Gloria's new coat."

19. Warn-speeding. Jerry was traveling by car to Chicago.

(He stopped at a rest area and met a friend of his, Kevin, traveling in the opposite direction.

Jerry was curious about the upcoming road conditions.

Jerry: "How's the road north of here?"

Kevin: "Watch out, there's a lot of cops around. I almost got caught speeding.")

He stopped at a rest area where he was supposed to meet Kevin, a friend of his.

Jerry was curious about why it had taken Kevin so long to get there.

Jerry: "Why did it take you so long to get here?"

Kevin: "There was a lot of cops around. I almost got caught speeding."

20. Reassure-moving. Lana heard from someone that her roommate, Monica, was thinking of moving out.

(Monica, however, had no intention of doing so.

Lana: "Someone told me you're thinking of moving out."

Monica: "I just want to make sure you know that I'm definitely not planning on moving out. I' $m$ staying here and rooming with you.")

Monica, as it turns out, was planning on doing just that.

Lana: "Someone told me you're thinking of moving out."

Monica: "I just want to make sure you know that I'm definitely thinking of moving out and not staying here and rooming with you."

21. Correct-proper. Ms. Middleton teaches fourth grade and really enjoys it. However, a problem has developed with some children using the word ain't.

One day the following exchange occurs:

(Johnny: "Why ain't we going to the library today?"

Mrs. Middleton: "The proper way is to say, "why aren't we going to the library today?"')

Johnny: "Why aren't we going to the library today?"

Mrs. Middleton: "I'm glad you didn't say, 'why ain't we going to the library today?'”

22. Invite—dinner. Some new people just moved into Sandi's neighborhood. They seem very nice and Sandi thought she'd like to get to know them better.

(One of her new neighbors was working in the yard.

Sandi went over to this person and introduced herself.

Then she said to them,

Sandi: "Would you like to come over for dinner tomorrow night?")

She had recently been making attempts to get together with them.

When she saw one of her neighbors working in the yard Sandi went over to them.

Sandi went over to this person and introduced herself.

Then she said to them,

Sandi: "Why didn't you come over for dinner last night?"

23. Excuse - feeling. Household chores were supposed to be shared equally by everyone in the house.

(Tom's been very busy lately and has not kept up his end of the bargain.

When asked why he hasn't helped more Tom says,

Tom: "I have not been feeling well.")

Tom's been very busy lately but has still kept up his end of the bargain.

When asked why he has been helping so much Tom says,

Tom: "I really have been feeling well."

24. Promise - neater. Kate has been very busy lately and has fallen behind in her household responsibilities.

In short, she's been a slob.

(She feels bad about this and wants her roommates to know that she will change her behavior beginning next week.

When she sees her roommates she says to them,

Kate: "I swear I will be neater after the weekend.")

After the weekend she changed and was much neater.

When she sees her roommates she says to them,

Kate: "I swear I was neater after the weekend." 